REVISTA X, Curitiba, volume 13, n.2, p.67-92, 2018.

\title{
FORMAÇÃO DE PROFESSORES EM UMA COMUNIDADE DE PRÁTICA: O CASO DO NUCLI INGLÊS SEM FRONTEIRAS NA UFPR
}

Teachers' education in a Community of Practice: the English without Borders Center case at UFPR

\author{
Angela Maria WALESKO (UFPR) ${ }^{1}$ \\ Fernanda FELIX (UFPR) ${ }^{2}$
}

RESUMO: Este artigo tem por objetivo descrever as práticas de um grupo de alunosprofessores do Núcleo de Língua Inglesa (NucLi Inglês) do Programa Idiomas sem Fronteiras da Universidade Federal do Paraná (IsF - UFPR), refletindo sobre como os membros desse grupo apresentam, em suas práticas, engajamento mútuo, empreendimento conjunto e um repertório compartilhado, caracterizando-o como uma Comunidade de Prática (CP), e como as interações e participação dos membros na comunidade promovem a aprendizagem e a trans/formação constante de suas identidades. Para isso, as reflexões têm por base principal textos de Lave (1988), Lave; Wenger (1991), Wenger (1998a, 1998b, 2000, 2002, 2010), de Wenger; Mc Dermott; Snyder (2002), de Kimble; Hildreth (2008), de Halu (2010), de Calvo et al (2014) e de Fogaça; Halu (2017). A caracterização do NucLi Inglês-IsF da UFPR como uma CP permite concebê-lo como um espaço de formação inicial que, por meio de interações e de práticas de estudo e de trabalho colaborativas, incentiva no aluno-professor o desenvolvimento do pensamento crítico-reflexivo e a capacidade de aplicar teorias à suas práticas, bem como de teorizar suas práticas e produzir conhecimento informado.

PALAVRAS-CHAVE: Comunidade de prática; formação de professores; língua inglesa.

ABSTRACT: This article intends to describe the practices of a pre-service teachers group from the English Language Center (NucLi Inglês) of the English without Borders Program at the Federal University of Paraná (IsF- UFPR). Here we consider how the members of this group present, in their practices, mutual engagement, a joint enterprise and a shared repertoire, which constitute a Community of Practice (CP), and how their interactions and participation within the community promote learning and the constant trans/formation of their identities. The discussions are structured over Lave (1988), Lave; Wenger (1991), Wenger (1998a, 1998b, 2000, 2002, 2010), Wenger; Mc Dermott; Snyder (2002), Kimble; Hildreth (2008), Halu (2010),Calvo et al (2014) and Fogaça; Halu (2017). The characterization of the English Center (NucLi UFPR) as a CoP allows us to conceive it as a space of initial teachers' education, which, through interaction, and collaborative study and work practices, fuels the pre-service teachers to develop their critical-reflexive awareness and their ability to apply theories to their practices, as well as to theorize their activities and produce informed knowledge.

KEY WORDS: Community of practice; teachers'education; English language.

\footnotetext{
${ }^{1}$ Professora no Departamento de Teoria e Prática de Ensino (DTPEN) da UFPR e doutoranda em Estudos Linguísticos no programa de Pós-Graduação em Letras da UFPR.

${ }^{2}$ Doutoranda em Estudos Linguísticos no programa de Pós-Graduação em Letras da UFPR.
} 


\section{INTRODUÇÃO}

A interação é, sem dúvida, indispensável para a constituição da identidade pessoal e profissional dos indivíduos. Como ressalta Bakhtin (apud SANTOS, 2004, p.164), "por meio do diálogo e da busca pela compreensão mútua, cada pessoa tenta ver o mundo através dos olhos do outro sem perder de vista o sentido de si mesmo". Desse modo, Comunidades de Prática (CPs), enquanto contextos simultaneamente homogêneos e heterogêneos de compartilhamento de práticas e de construção, negociação e reconstrução de significados, apresentam-se como importantes espaços de formação inicial e continuada de professores e, portanto, espaços de aprendizagem e para se pensar sobre ensino e sobre aprendizagem.

Percebendo o Núcleo de Língua Inglesa (NucLi Inglês) do Programa Idiomas sem Fronteiras da Universidade Federal do Paraná (IsF - UFPR) como um desses espaços de aprendizagem (do qual fomos participantes entre os anos de 2014 e 2016), onde licenciandos em Letras-Inglês têm a oportunidade de aprender a ser professores, de construírem e reconstruírem suas identidades pessoais e profissionais, por meio do diálogo e de práticas colaborativas em um grupo, observamos que fazíamos parte de uma Comunidade de Prática que, embora não fosse oficialmente nomeada como tal, era formada por membros cujas práticas discursivas e cujo desejo de consenso, de partilhar valores, de construir visões comuns e definir objetivos (HALU, 2010, p. 58, 59) the davam tal identidade. Acreditamos que compartilhar, neste texto, reflexões sobre essas práticas e desejos, bem como sobre a estruturação de Comunidades de Prática e do NucLi Inglês-IsF da UFPR como uma CP, possa contribuir para novos olhares, por parte de instituições formadoras e de formadores de professores, em relação a espaços de formação inicial já existentes e a espaços que venham a ser constituídos, como uma alternativa às ações isoladas e pontuais bastante comuns nas Instituições de Ensino Superior, nas quais muito se fala sobre práticas, mas pouco se aprende nas e com as práticas - discursivas, situadas e colaborativas. Contrárias à concepção de aprendizagem como um processo individual e descontextualizado de aquisição do conhecimento que, segundo Wenger (1998) é “irrelevante, chato e árduo" acreditamos que a formação de professores em Comunidades de Prática promove, nas palavras de Wenger,

modos criativos de engajar os alunos em práticas significativas, de prover o acesso a recursos que ampliem sua participação, de abrir horizontes para que eles possam se colocar em trajetórias de aprendizagem com as quais se 
identificam, e de envolvê-los em ações, discussões e reflexões que façam diferença para as comunidades que valorizam ${ }^{3}$ (WENGER, 1998a, p.10).

Partindo desses princípios e com o objetivo de apresentar e discutir práticas, experiências e reflexões vivenciadas em nosso trabalho pedagógico no Programa IsF e teorizadas em nossos estudos no curso de Pós-graduação em Letras na UFPR, caracterizamos o Núcleo de Língua Inglesa (NucLi Inglês) do Programa Idiomas sem Fronteiras da Universidade Federal do Paraná (IsF - UFPR) como uma Comunidade de Prática (CP), apresentando, para isso, um referencial teórico que traz uma breve descrição da definição e características de uma CP a partir de textos de Lave (1988), Lave; Wenger (1991), Wenger (1998a, 1998b, 2000, 2002, 2010), de Wenger; McDermott; Snyder (2002), de Kimble; Hildreth (2008), de Halu (2010), de Calvo et al (2014) e de Fogaça; Halu (2017). Na sequência, relacionamos tal referencial às práticas desenvolvidas e às narrativas de seus participantes, além de apresentarmos uma reflexão sobre as identidades dos membros dessa $\mathrm{CP}$, que estariam em constante re/construção de acordo com as práticas situadas vivenciadas no grupo. Também julgamos relevante apresentar um breve histórico sobre o Programa Idiomas sem Fronteiras (IsF) e sobre o surgimento do Núcleo de Língua Inglesa (NucLi Inglês) da UFPR enquanto espaço de formação docente, para situar os leitores deste texto e facilitar seu entendimento sobre as razões pelas quais consideramos esse espaço uma Comunidade de Prática.

\section{COMUNIDADE DE PRÁTICA: REFERENCIAL TEÓRICO}

Em seu livro Communities of Practice - Learning, Meaning and Identity (1998a, p. 6) Ettiene Wenger explica que Comunidades de Prática estão em todo lugar, uma vez que todos nós pertencemos a Comunidades de Prática - em casa, na escola, no trabalho, etc. - que mudam ao longo de nossas vidas. Entretanto, Wenger esclarece que nem toda comunidade pode ser considerada uma Comunidade de Prática:

Os membros de uma comunidade são informalmente vinculados pelo que fazem juntos $[\ldots]$ e pelo que aprenderam através de seu engajamento mútuo nessas atividades. Uma comunidade de prática é, assim, diferente de uma

\footnotetext{
${ }^{3}[\ldots]$ inventive ways of engaging students in meaningful practices, of providing access to resources that enhance their participation, of opening their horizons so they can put themselves on learning trajectories they can identify with, and of involving them in actions, discussions, and reflections that make a difference to the communities that they value.
} 
REVISTA X, Curitiba, volume 13, n.2, p.67-92, 2018.

comunidade de interesse ou uma comunidade geográfica, sem que nenhuma delas implique uma prática compartilhada ${ }^{4}$. (WENGER, 1998b, p. 2).

Para Wenger (1998b, p. 4), “comunidades de prática diferem de outros grupos encontrados em organizações pela forma como definem seu empreendimento, existem ao longo do tempo e estabelecem seu limites"5. Uma Comunidade de Prática, portanto, não é constituída pelo simples agrupamento de pessoas, mas sim por grupos que se engajam em práticas compartilhadas em prol de objetivos comuns ao longo de um determinado período de tempo, desenvolvendo, para isso, um repertório linguístico/discursivo compartilhado que permita a negociação de significados. A aprendizagem decorrente da interação dos membros da comunidade, uns com os outros, bem como com outras pessoas, com as coisas, com o mundo, gera aprendizagem, que resulta de e em práticas coletivas, situadas e colaborativas, envolvendo diferentes relações, tais como as interculturais, entre identidades e de poder.

Wenger (2010, p. 179) contextualiza o conceito de Comunidade de Prática, que “tem suas raízes em tentativas de desenvolver narrativas sobre a natureza social da aprendizagem humana [...]" ${ }^{6}$; para ele, uma CP pode ser analisada como um sistema social, constituído por outros sistemas sociais inter-relacionados. O autor explica que “[...] ela exibe muitas características de sistemas de forma mais geral: estrutura emergente, relações complexas, auto-organização, fronteiras dinâmicas, contínuas negociações entre identidades e significados culturais, para mencionar algumas"7 (Wenger, 2010, p.179).

O conceito de Comunidade de Prática, inspirado pela Antropologia e pelas Teorias Sociais de Lave (1988), Bourdieu (1977), Giddens (1991), Foucault (1983) e Vygotsky (1978), tem origem nas tentativas de compreender a natureza social da aprendizagem, atentando para os fenômenos das práticas sociais, de identidade, questões de poder e de formação de significados (WENGER, 2010). O desenvolvimento do indivíduo e da sociedade a partir da vivência social, de experiências e análises situadas e contextualizadas cultural e historicamente, a mediação das experiências no

\footnotetext{
${ }^{4}$ Members of a community are informally bound by what they do together [...] and by what they have learned through their mutual engagement in these activities. A community of practice is thus different from a community of interest or a geographical community, neither of which implies a shared practice.

${ }^{5}$ Communities of practice differ from other kinds of groups found in organizations in the way they define their enterprise, exist over time, and set their boundaries.

${ }^{6}$ It has its roots in attempts to develop accounts of the social nature of human learning [...].

7 [...] it exhibits many characteristics of systems more generally: emergent structure, complex relationships, self-organization, dynamic boundaries, ongoing negotiation of identity and cultural meaning, to mention a few.
} 
REVISTA X, Curitiba, volume 13, n.2, p.67-92, 2018.

mundo e sua constituição dialógica são algumas perspectivas dessa corrente que dão foco aos entendimentos dos pioneiros na abordagem de Comunidades de Prática.

Desde seu cunho, por Lave e Wenger (1991), o termo "Comunidades de Prática" teve seu escopo ampliado e facetado em diferentes áreas do conhecimento. Em análises teóricas e trabalhos acadêmicos, nos setores organizacional, governamental, educacional, de saúde e civil brotaram e floresceram experiências envolvendo o termo.

Wenger (2010) defende que a disseminação do termo pode tanto ter resultados positivos quanto negativos. Quando, através da simples abordagem do tema, questões que tangem o fenômeno das Comunidades de Prática, como trabalho entre pares, aprendizagem em contexto social e questões de identidade, têm cada vez mais espaço para serem debatidas, incorporadas e desenvolvidas, a utilização dos conceitos está sendo vantajosa. Quando o termo se distancia de suas origens e é encarcerado em estratégias de gestão, tanto críticas são pertinentes quanto muitas vezes se percebe o fracasso da sua aplicação.

Para Wenger, Mc Dermott e Snyder (2002, p. 35), uma base comum o suficiente para facilitar o engajamento mútuo e uma boa dose de diversidade podem levar a uma "[...] aprendizagem mais rica e a relacionamentos mais interessantes", além de aumentarem a criatividade dentro de uma CP. Os conflitos, que sempre existirão em qualquer comunidade marcam, portanto, a heterogeneidade e são bastante produtivos, uma vez que permitem aos membros da $\mathrm{CP}$ "examinar diferenças de crenças, solicitar vozes alternativas, construir pontes entre diferenças em direção a um solo comum e procurar oportunidades para mudança e crescimento" (HALU, 2010, p. 60). Segundo Halu (2010, p.60), uma Comunidade de Prática é "um organismo dinâmico, com fronteiras e objetivos também dinâmicos". Ainda para a autora, "toda comunidade enfrenta o desafio de desenvolver um equilíbrio dinâmico entre seus desejos de consenso e mudança, tendo de lidar com conflitos como elemento constante em sua existência" (ibidem).

Além disso, se considerarmos que cada membro de uma CP tem uma formação diferente, participa de diferentes práticas nas demais comunidades de que faz parte e possui diferentes identidades, em constante re/construção, podemos afirmar que toda e qualquer Comunidade de Prática será sempre heterogênea.

\footnotetext{
${ }^{8}[\ldots]$ richer learning, more interesting relationships $[\ldots]$.
} 
REVISTA X, Curitiba, volume 13, n.2, p.67-92, 2018.

O que se percebe é que uma Comunidade de Prática pode emergir de forma espontânea em um contexto, assumindo características que podem ser entendidas como estruturantes, porém ser analisada como tal somente depois do seu surgimento, ou nunca o ser, o que não nega sua existência. Seu surgimento também pode também se dar de forma estruturada, incentivada, delimitando-se pontos fundamentais que, para determinado fim, são englobados em uma experiência à qual se dá o nome de Comunidade de Prática.

O desenvolvimento de uma CP é entendido como dinâmico (LAVE, 1988; LAVE; WENGER, 1991; WENGER, 1998a,b): objetivo, organizações de papéis de atuação e paradigmas vão se delimitando, se reformulando e se reafirmando durante o desenvolvimento do fenômeno. A participação de cada indivíduo se estrutura dialogicamente com o desenvolvimento da CP. Tanto a intensidade da participação colabora com a formatação momentânea do fenômeno quanto tudo que ocorre na comunidade colabora com a estruturação da participação de cada um. Concebendo participação intrinsicamente conectada à aprendizagem, Wenger (1998b) explica que a aprendizagem acontece através do nosso envolvimento em ações e interações e que através disso a aprendizagem reproduz e transforma a estrutura social na qual tem lugar. $\mathrm{O}$ autor aponta engajamento mútuo, empreendimento conjunto e repertório compartilhado (1998a, p. 73) como três dimensões da relação entre prática e comunidade, necessárias para que uma comunidade seja caracterizada como uma Comunidade de Prática, diferenciando-se de uma comunidade de interesse ou de uma comunidade geográfica, por exemplo. Isso significa que, em uma $\mathrm{CP}$, em suas práticas, os participantes engajam-se em prol de objetivos comuns compartilhando um repertório que inclui um discurso que pode ser heterogêneo, mas coerente.

O engajamento mútuo, como uma das dimensões da relação entre prática e comunidade, vincula os membros de uma CP nas práticas situadas pelas atividades que realizam juntos e pelo que aprendem juntos nessas práticas. A prática compartilhada e a aprendizagem decorrem de tal engajamento, que pode ser diferente de um membro para outro e de uma prática para outra e conflitos que possam surgir pela heterogeneidade da comunidade são vistos como produtivos por possibilitarem a reavaliação e a reformulação de objetivos e estratégias nas práticas da comunidade. O engajamento é também, segundo Wenger, uma forma de pertencimento, pois "as maneiras nas quais nos engajamos uns com os outros e com o mundo moldam profundamente nossa 
REVISTA X, Curitiba, volume 13, n.2, p.67-92, 2018.

experiência de quem somos. Aprendemos o que podemos fazer e como o mundo responde a nossas ações" ${ }^{9}$ (WENGER, 2000, p. 227).

O estabelecimento de um empreendimento conjunto, como uma segunda dimensão da relação entre prática e comunidade implica na negociação entre os membros da comunidade para a definição de objetivos comuns e essa negociação envolve, segundo Wenger, relações de responsabilidade, uma vez que

[...] incluem o que importa ou não, o que é importante e por que é importante, o que fazer ou não, o que prestar atenção e o que ignorar, sobre o que falar e o que deixar não dito, o que justificar e o que tomar como certo, o que mostrar e o que ocultar, quando as ações e os artefatos são bons o suficiente e quando eles precisam de aprimoramento ou refinamento ${ }^{10}$. (WENGER, 1998a, p. 81).

Com um empreendimento conjunto estabelecido a compartilhar, a Comunidade de Prática desenvolverá um repertório compartilhado, terceira dimensão da relação entreprática e comunidade, proposta por Wenger. $\mathrm{O}$ autor argumenta que tal repertório "inclui o discurso pelo qual os membros criam afirmações significativas sobre o mundo, e também sobre os estilos pelos quais expressam suas formas de pertencimento e suas identidades como membros" ${ }^{11}$ (WENGER, 1998a, p. 83). Embora o repertório possa ser bastante heterogêneo entre os membros de uma CP ele ainda será coerente visto que todos têm um ou mais propósitos em comum nas práticas que realizam na comunidade.

Wenger (1998b) destaca formas de análise de participação que são determinantes para os seus entendimentos sobre comunidades de prática. Ele acredita que tanto a periferalidade quanto a marginalidade são atributos de participação entre os indivíduos e aponta: "No caso da periferalidade, algum grau de não participação é necessário para permitir um tipo de participação que é menos que completo"12 (WENGER, 1998a, p. 165). Esse é o caso de um indivíduo recém-chegado em um grupo que constitui uma Comunidade de Prática, por exemplo. Ele pode construir a trajetória de sua participação de uma posição periférica para uma plena, com o

\footnotetext{
${ }^{9}$ The ways in which we engage with each other and with the world profoundly shape of experience our who we are. We learn what we can do and how the world responds to our actions.

${ }^{10}[\ldots]$ include what matters and what does not, what is important and why it is important, what to do and not to do, what to pay attention to and what to ignore, what to talk about and what to leave unsaid, what to justify and what to take for granted, what to display and what to withhold, when actions and artifacts are good enough and when they need improvement or refinement.

${ }^{11}$ It includes the discourse by which members create meaningful statements about the world, as well as the styles by which they express their forms of membership and their identities as members.

${ }^{12}$ In the case of peripherality, some degree of non-participation is necessary to enable a kind of participation that is less than full.
} 
REVISTA X, Curitiba, volume 13, n.2, p.67-92, 2018.

desenvolvimento dos eventos. É justamente nesse processo que a aprendizagem encontra sua realização mais plena (LAVE, 1988; LAVE; WENGER, 1991; WENGER, 1998a). Ainda para Wenger, "no caso a marginalidade, uma forma de não participação, previne a participação plena"13 (1998a, p. 166), como quando se percebe o processo de desligamento gradual de um indivíduo que se aposenta. A periferalidade e a legitimação são movimentos necessários para a participação plena em qualquer CP. A antropóloga Jean Lave (1988, p. 53) apresenta esse fenômeno como uma "trajetória ascendente de aprendizagem”.

É importante ressaltar que embora se use os termos marginal, periférico e pleno, uma comunidade de prática não apresenta um centro, almejado pelos participantes ao ingressarem. Sua participação pode ser diferente a cada prática situada e/ou mudar ao longo da repetição dessa prática, ou seja, dependendo do alinhamento do participante com uma determinada prática, ele/ela se engajará mais ou menos, ou não se engajará, assumindo uma posição plena, periférica ou marginal.

O que justifica uma CP é a aprendizagem dos indivíduos que tem lugar em seu decurso. E essa aprendizagem é possível graças à interação das histórias de aprendizagem de cada indivíduo compartilhadas. Wenger e Lave buscaram expandir as conotações tradicionais do conceito de aprendizagem de uma relação mestre/estudante ou mentor/tutelado para uma de participação dinâmica e transformação de identidade em uma CP (WENGER, 1998b). Para Wenger (1998a), a aprendizagem é uma característica da prática e as formas de participação e reificação são modos de existência duais que afetam a si mesmos e continuamente convergem e divergem, formando uma unidade na sua dualidade. A participação dos membros em práticas de uma comunidade envolve, entre outros aspectos, ação, mutualidade, interação e afiliação, que necessitam ser reificados através da linguagem, da negociação discursiva e não discursiva, ou seja, criam materialidade ou são "coisificados" em ideias, conceitos, documentos, instrumentos, objetos, artefatos, etc., em constante transformação. Através dessas dinâmicas internas ao indivíduo e entre os participantes e as diversas comunidades de prática de que fazem parte, acontece a aprendizagem.

\section{COMUNIDADES DE PRÁTICA: IDENTIDADES EM CONSTANTE RE/CONSTRUÇÃO}

\footnotetext{
${ }^{13}$ In the case of marginality, a form of non-participation prevents full participation.
} 
É fundamental à concepção de Comunidade de Prática que temos apresentado a ideia de que no processo de desenvolvimento de uma $\mathrm{CP}$, de aprendizagem dos envolvidos, ocorre também a construção e reconstrução de identidades. A partir de uma perspectiva sócio construtivista (VYGOTSKY, 1994; WENGER, 1998a), a identidade é co-construída nas várias relações sociais que as pessoas vivem e nas quais se engajam (BRADLEY, 1996) e não são fixas, estruturadas estaticamente. Para Sarup (1996, p.26), "a identidade não é algo que encontremos e que tenhamos de uma vez e para sempre. Identidade é um processo".

"Nossas identidades são ricas e complexas porque são produzidas dentro de um conjunto rico e complexo de relações de prática"14 (WENGER, 1998, p. 162). Assim como a CP vai desenvolvendo características que a configuram, tais como a delimitação de seus objetivos, e que essas características vão sendo confrontadas, retificadas ou reformuladas, a identidade dos indivíduos que a constituem também são envolvidas nas experiências da $\mathrm{CP}$ e também passam por confrontos, retificações e reformulações.

Hall (1992) defende que a identidade é construída no discurso, que é através do discurso que as pessoas constroem suas identidades sociais e se posicionam no mundo. Wenger (1998a) também propõe que cada ato de participação, cada ato de agência, reflete a constituição mútua entre indivíduos e coletivos.

Identidade na prática é definida socialmente porque é produzida como uma experiência vivida de participação em comunidades específicas. Quais narrativas, categorias, papéis e posições vêm a significar como uma experiência de participação é algo que deve ser trabalhado na prática. ${ }^{15}$ (p.151)

Portanto, um acumulado de eventos de participação e reificação, através de experiências individuais e sociais e dos efeitos no mundo que elas provocam, vai desenvolvendo as identidades. A esse respeito Block (2010, p. 27) observa que

O trabalho com a identidade ocorre na companhia de outros - seja face-a-face ou de um modo mediado eletronicamente - com quem os indivíduos dividem, em vários níveis, crenças, intenções, valores, atividades e práticas. As

\footnotetext{
${ }^{14}[\ldots]$ our identities are rich and complex because they are produced within the rich and complex relations of practice.

${ }^{15}$ Identity in practice is socially defined because it is produced as a lived experience of participation and multimembership in specific communities. What stories, categories, roles, and positions might mean as experiences of participation is worked out in practice.
} 
identidades estão relacionadas à negociação de novas posições de sujeito no cruzamento do passado, presente e futuro $[\ldots]^{16}$.

Wenger defende que para compreendermos o desenvolvimento de identidades, inclusive da identidade da própria $\mathrm{CP}$, é necessário que tenhamos sob análise três formas de pertencimento a essa comunidade: a) imaginação; b) engajamento e c) alinhamento (FOGAÇA; HALU, 2017).

A imaginação (WENGER, 1998a, p. 173, tradução nossa) tem a ver com "a criação de imagens do mundo, e a percepção de conexões no tempo e espaço, extrapolando nossa própria experiência”. O engajamento se refere ao “envolvimento mútuo em processos de negociação de significados”. Já o alinhamento (WENGER, 1998a, p. 178-179, tradução nossa) "articula o tempo e o espaço para empreendimentos maiores, a fim de que os participantes se conectem pela coordenação de suas energias, ações e práticas”. (FOGAÇA; HALU, 2017, p. 434-435).

O que os autores propõem é uma percepção da esfera "imaginada" do desenvolvimento identitário. Fundamentados em Norton (2013), atentam para a transcendência possível através da imaginação e para a capacidade de alcançar novas possibilidades de experiência da Comunidade de Prática e novas possibilidades de experiência das suas próprias identidades. Para Kanno e Norton (2003, p. 248), "nossas identidades podem ser compreendidas não apenas em termos de 'investimento' em um mundo 'real', mas também de nosso investimento em mundos possíveis" ${ }^{17}$.

Considerando, portanto, que as identidades surgem discursivamente, nas relações, que são fluxos que se relacionam com os momentos e as experiências temporalmente situados e também com fenômenos imaginados, constatamos que questões de poder estão inerentemente envolvidas no desenvolvimento identitário. Nos atos discursivos estão envolvidas relações de poder que, na medida em que se configuram, implicam no desenvolvimento das identidades e dos espaços sociais discursivos. Wenger (1998a) adverte sobre as questões de poder que envolvem as Comunidades de Prática. Ele indica que embora elas tenham um caráter autônomo e dinâmico, isso não exclui as influências e formatações advindas do contexto em que se dão, seja ele institucional, político, cultural. Para ele, a existência de uma comunidade significa que há competências almejadas pelos aprendizes, algo em comum pelo que

\footnotetext{
${ }^{16}$ Identity work occurs in the company of others - either face-to-face or in an electronically mediated mode - with whom to varying degrees individuals share beliefs, motives, values, activities and practices. Identities are about negotiating new subject positions at the crossroads of the past, present and future [...].
} 
combater, significados a definir e apropriar. Na linguagem da teoria, uma Comunidade de Prática cria uma economia de significados (WENGER, 2010, p. 8). A negociação de significados aos quais se identificam ou não os participantes é experiência fundamental à aprendizagem e à reformulação ou retificação das identidades dos participantes e da própria CP. Segundo Wenger (1998a) a negociação entre as identidades e os significados está sempre sob influência de questões de poder.

O reconhecimento das relações de poder como implicadas nos processos de formação de identidade apresenta-se em Lave e Wenger (1991) consistentemente com as concepções de poder e discurso em Foucault (1983, 1991). Fox (2000) busca expandir essas concepções e esclarece que o poder é relacional e produtivo, estando diretamente ligado ao desenvolvimento de conhecimento. Para ele, mudanças de discurso representam mudanças de conhecimento e de relações de poder.

Dessa maneira, a modulação das identificações na construção, reconstrução e retificação das identidades em uma Comunidade de Prática podem aparecer como um fenômeno que permite relações menos verticais (WENGER, 1998a). Os aspectos colaborativos e as práticas compartilhadas que tanto configuram a $\mathrm{CP}$ quanto fazem parte dos processos de construção e desenvolvimento de identidade são, em certa medida, fenômenos capazes de oferecer estruturas mais horizontais de poder, em que os sujeitos constroem relações de significados em processos de menos detrimento entre si.

\section{BREVE HISTÓRICO DO PROGRAMA IDIOMAS SEM FRONTEIRAS (IsF) E DO NÚCLEO DE LÍNGUA INGLESA DA UFPR (NucLi Inglês -- UFPR)}

A fim de atender às demandas do programa Ciência sem Fronteiras $(\mathrm{CsF})$, criado em 2011, e de outros programas de intercâmbio governamentais, o governo federal, em conjunto com o Ministério da Educação e da Cultura (MEC), a Secretaria de Educação Superior (SESu) e a Coordenação de Aperfeiçoamento de Pessoal de Nível Superior (CAPES) criaram, em 2012, o programa Inglês sem Fronteiras (IsF).

\footnotetext{
O programa Inglês sem Fronteiras (IsF) foi elaborado a partir da necessidade de se aprimorar a proficiência em língua inglesa dos estudantes universitários brasileiros com o objetivo de proporcionar oportunidades de acesso, através do programa Ciência sem Fronteiras, a universidades de países onde a educação superior é conduzida em sua totalidade ou em parte por meio da língua inglesa (BRASIL, 2014).
}

\footnotetext{
${ }^{17}$ Our identities then must be understood not only in terms of our investment in the "real" world but also in terms of our investment in possible worlds.
} 
Ao final do ano de 2012, a Universidade Federal do Paraná (UFPR) e o MEC iniciaram as negociações para a implantação do programa Inglês sem Fronteiras (IsF), com o apoio do Centro de Línguas e Interculturalidade (CELIN) e do Núcleo de Assessoria Pedagógica (NAP) da UFPR, que lhe cederam espaço físico e estrutura para o planejamento e realização de suas atividades a partir do segundo semestre de 2013.

O sucesso do programa Inglês sem Fronteiras em mais de 60 universidades federais brasileiras promoveu o surgimento do programa Idiomas sem Fronteiras, a partir de 2015. A sigla IsF passou a ser utilizada então como abreviação de "Idiomas sem Fronteiras", um programa que tem como principal objetivo incentivar o aprendizado de línguas e a formação inicial de professores, além de propiciar uma mudança abrangente e estruturante no ensino de idiomas estrangeiros nas universidades do país. O programa IsF na UFPR mantém hoje ações para o ensino e aprendizagem das línguas inglesa, francesa, alemã, italiana, japonesa e espanhola, além do português como língua estrangeira.

\section{A equipe NucLi Inglês-IsF da UFPR}

Desde seu início em 2013 até o final de 2016, a equipe NucLi Inglês-IsF da UFPR foi formada por cerca de dez professores-bolsistas, dois coordenadores (um geral e um pedagógico), uma professora do Curso de Letras, que auxiliou técnica e pedagogicamente, uma técnica do CELIN, três estagiários/monitores e dez ETAs (English Teaching Assistants), bolsistas estadunidenses do Programa English Teaching Assistant ${ }^{18}$, sendo que três ETAs participaram da equipe em 2014, quatro em 2015 e três em 2016.

Os professores-bolsistas (alunos-professores) do NucLi Inglês-IsF da UFPR são estudantes do curso de Letras, licenciatura em língua inglesa, que apresentam um bom histórico escolar e possuem o score mínimo (600 pontos) exigido pelo programa no Teste de Inglês como Língua Estrangeira (Test of English as a Foreign Language TOEFL, na modalidade ITP - Institutional Testing Program). Alguns deles já possuem alguma experiência em sala por lecionarem em institutos de idiomas ou em projetos da universidade e alguns não têm nenhuma experiência docente.

\footnotetext{
${ }^{18} \mathrm{O}$ English Teaching Assistant (ETA) Program é uma iniciativa do governo federal como expansão do programa CAPES-Fullbright, que visa apoiar e aprimorar as condições estruturantes para a oferta de ensino do idioma estrangeiro de forma mais rápida e mais eficaz.
} 
REVISTA X, Curitiba, volume 13, n.2, p.67-92, 2018.

Os professores formadores dos professores-bolsistas, coordenadores do NucLi Inglês-IsF, são professores mestres e doutores, que atuam também na graduação e pósgraduação do curso de Letras - Inglês da UFPR, no Departamento de Línguas estrangeiras e no Departamento de Teoria e Prática de Ensino da mesma universidade.

Os ETAs (English Teaching Assistants) são alunos estadunidenses graduados em áreas diversas (preferencialmente relacionadas ao ensino e aprendizagem de línguas) com interesse no ensino e aprendizagem de língua inglesa e portuguesa e na cultura brasileira; o programa ETAs tem, entre seus principais objetivos "fomentar experiências metodológicas e práticas de caráter inovador nos processos de ensino e aprendizagem dos futuros docentes e estudantes da língua inglesa e fomentar propostas que contemplem a inclusão de conteúdos culturais, sociais e históricos da sociedade norteamericana na formação dos futuros docentes e estudantes brasileiros" (Projeto ETA UFPR 2013).

As línguas, mas principalmente a língua inglesa é, entre os envolvidos no programa Idiomas sem Fronteiras, um marco comum que caracteriza a homogeneidade no grupo geral, além da homogeneidade presente em cada subgrupo. A homogeneidade também se faz presente nos interesses, objetivos e práticas realizadas em conjunto, entre outras questões. Mas é a heterogeneidade do grupo que promove e enriquece ainda mais a aprendizagem por meio de troca de conhecimento e experiências. Tanto a homogeneidade quanto a heterogeneidade, são, entre outras características descritas ao longo deste texto, aspectos que identificam o NucLi Inglês-IsF da UFPR como uma CP.

\section{O NucLi Inglês-IsF da UFPR como uma CP}

O Núcleo de Língua (NucLi) - Inglês UFPR, dentro de toda a estruturação do programa Idiomas sem Fronteiras (IsF) se configura como uma Comunidade de Prática (CP) que surge espontaneamente, ainda que dentro de um outro sistema social organizado,ou seja, mesmo que o grupo de membros desse Núcleo de Língua fosse institucionalmente identificado (pela UFPR, pelo IsF ou pelo MEC) como uma CP, tal identificação não lhe garantiria a caracterização de $\mathrm{CP}$, pois essa depende fundamentalmente do engajamento mútuo de seus membros por meio da negociação de significados em práticas situadas em prol de objetivos conjuntos; e é na participação nessas práticas que a aprendizagem acontece, não no sentido de "adquirir habilidades ou obter informações, mas de tornar-se uma determinada pessoa - um conhecedor em 
um contexto em que o que significa conhecer é negociado em relação ao regime de competência de uma comunidade"19 (WENGER, 2010, p.180). Como explica Wenger

[p]ode-se planejar sistemas de responsabilidade e políticas para guiar a vida de comunidades de práticas, mas não se pode planejar as práticas que irão emergir em resposta a tais sistemas institucionais. [...] Pode-se tentar institucionalizar uma comunidade de prática, mas a comunidade de prática por si mesma irá escapar pelas rachaduras e permanecer distinta de sua institucionalização $^{20}$. (WENGER, 1998, p. 229).

O Núcleo de Língua (NucLi) - Inglês UFPR se caracteriza como uma Comunidade de Prática por apresentar os aspectos engajamento mútuo, empreendimento conjunto e repertório compartilhado nas diversas práticas situadas (descritas a seguir, neste texto), que permitem a participação de seus membros em diferentes posições (marginal, periférica e plena). O engajamento de cada um em cada prática da comunidade dependerá do quanto e de como esse membro se identifica com a prática e com o/s objetivo/s do empreendimento; o construto sociológico "investimento" (NORTON, 1995) pode ser utilizado nas discussões sobre identidades e práticas em comunidades uma vez que o quanto cada membro investe, em termos de tempo e energia, em especial, depende dos processos de identificação com tal/tais objetivos e com os demais membros o que, por sua vez, influenciará na re/construção de suas identidades.

Dentro dos processos de formação no modelo de aprendizagem colaborativa seus membros, formadores e professores em formação, constituem uma comunidade de aprendizagem, em uma metodologia de trabalho-ensino-pesquisa. Essa comunidade enxerga a colaboração por meio do espectro da ação dialógica, possibilitando aos seus membros a construção de saberes coletivos (WALESKO; LUCHESA, 2015). Assim, o trabalho colaborativo na equipe a torna uma $\mathrm{CP}$ na medida em que, segundo Wenger (1998a), se estabelece engajamento mútuo, negociação de um empreendimento conjunto e construção de um repertório de recursos - rotinas, ferramentas, conceitos, gestos e histórias.

19 ...not just acquiring skills and information; it is becoming a certain person - a knower in a context where what it means to know is negotiated with respect to the regime of competence of a community.

${ }^{20}$ One can design systems of accountability and policies for communities of practice to live by, but one cannot design the practices that will emerge in response to such institutional systems. [...] One can attempt to institutionalize a community of practice, but the community of practice itself will slip through the cracks and remain distinct from its institutionalization. 
REVISTA X, Curitiba, volume 13, n.2, p.67-92, 2018.

Listamos e brevemente descrevemos, a seguir, as principais práticas situadas, colaborativas, desenvolvidas pelo Nucli Inglês-IsF da UFPR entre 2014 e 2016, relacionando-as aos aspectos teóricos que definem Comunidades de Prática, segundo Wenger (1998a, 1998b, 2000, 2010) para caracterizar o NucLi Inglês-IsF da UFPR como uma CP.

\section{Práticas de planejamento}

Cada aluno-professor do NucLi Inglês-IsF da UFPR ministrava, entre 2014 e 2016, 12 horas/aula semanais de aulas de inglês para alunos de graduação e pósgraduação da universidade, seus técnicos e demais funcionários. Algumas horas das 20 horas semanais de atuação no IsF também correspondiam à prática de planejamento dessas aulas, que era realizado individualmente em casa e em parceria com os demais bolsistas, em encontros presenciais e virtuais, sob a proposta de que houvesse compartilhamento de ideias e materiais e, por sua vez, melhoria na qualidade das aulas. Relacionando a prática de planejamento com a teoria sobre o desenvolvimento de uma $\mathrm{CP}$, proposta por Wenger (1998a), observamos, enquanto membros integrantes da comunidade, que a maioria dos alunos-professores do NucLi Inglês-IsF da UFPR encontrava-se presencialmente com frequência para discutir problemas similares, ou o faziam por e-mail, voluntariamente. Por se tratar da existência de situações em que a colaboração é promovida e trabalhada para se alcançar desenvolvimento e aprendizagem acreditamos que essa prática de planejamento caracteriza uma estrutura fundamental às Comunidades de Prática. Assim sendo, aprender na prática inclui para a comunidade envolvida os processos de: desenvolver formas de engajamento mútuo, entender e afinar seu empreendimento, e desenvolver seu repertório, estilos e discursos (WENGER, 1998b). O planejamento (de materiais, aulas, avaliações) como uma prática situada colaborativa, e sua aplicação em sala, com resultados positivos, ou não, é uma prática que promove a aprendizagem e a trans/formação das identidades, pessoais e profissionais do aluno-professor, nesta e em outras comunidades às quais pertence.

\section{Encontros de formação de professores}

Entre 2014 e 2016 os encontros de formação de professores ocorreram ao longo de todas as sextas-feiras, com a duração de três horas, dos quais participaram a coordenação geral e pedagógica, a assessoria administrativa, alunos-professores e ETAs, para discussão de questões administrativas relacionadas às aulas presenciais e à 
REVISTA X, Curitiba, volume 13, n.2, p.67-92, 2018.

aplicação do exame TOEFL realizada pelo grupo, o andamento das aulas, planejamentos, divulgação, projetos e eventos, além de discussões de textos teóricometodológicos, organização, participação e realização de workshops. Tais encontros proporcionaram interação, senso de pertencimento e responsabilidade mútua e aprendizagem pessoal e profissional em sentidos variados. A interação contínua e regular com o propósito comum de aperfeiçoamento fez com que a equipe, enquanto uma CP, estabelecesse o que Wenger chamou de "parceria de aprendizagem" desenvolvendo, para isso, modos compartilhados de recursos e ações que se tornam importantes para suas práticas (CALVO et al., 2014).

Ao serem indagados sobre a validade dos encontros semanais, todos os professores em formação salientaram a importância e a relevância de sua continuidade. A professora L. S (2014) afirmou que

[o] encontro semanal com a equipe de professores e de coordenadores foi de extrema importância para meu crescimento como profissional; a oportunidade de entrar em contato com os colegas para troca de informações e experiências é essencial para mantermos a confiança e a segurança em sala de aula, além de criarmos o espírito de equipe com o grupo.

Segundo a professora aluna A.C (2014),

a interação com as outras professoras influiu diretamente na minha performance em sala de aula, pois através desse relacionamento pudemos trocar ideias, tarefas, dicas e até dividir preocupações, sejam relacionadas a um curso específico ou a um problema de relação estudante $\mathrm{x}$ professor. Neste quesito, especialmente, a intervenção e ajuda das coordenadoras também foi crucial.

Analisando os discursos das professoras-bolsistas, citamos Santos e Arroio (2015, p. 32), que fazem a seguinte declaração:

O conceito de comunidades de prática (...) remete à formação do sujeito por meio da interação com um grupo de pessoas em torno de uma prática em comum. Deste modo, a aprendizagem em comunidades de prática não se refere somente às discussões teóricas com o grupo, nem mesmo se limita apenas à prática. A aprendizagem em comunidades de prática se dá pelo compartilhamento de conhecimentos e pela aplicação de tais conhecimentos em situação de prática".

Hildreth e Kimble (2008, p.x), na introdução de sua edição de Communities of practice: creating learning environments for educators, declaram que “[...] professores 
REVISTA X, Curitiba, volume 13, n.2, p.67-92, 2018.

são claramente candidatos ideais para se beneficiar de CPs, já que podem ser poderosos catalisadores para permitir que professores melhorem sua prática ${ }^{21}$ ".

Nos discursos das professoras-bolsistas é evidente que a prática trouxe aprendizagem e que o engajamento mútuo e a colaboração permitiram o desenvolvimento de momentos de construção de práticas e identidades profissionais e pessoais, tanto através da identificação quanto do estranhamento.

\section{O Projeto de Observação de Aulas}

A observação de aulas é uma prática colaborativa e reflexiva importantíssima para o desenvolvimento pedagógico e aprimoramento didático docente. Paulo Freire enfatizou o papel essencial da reflexão para a prática docente. Para Freire, a reflexão se encontra no pensar para o fazer e no pensar sobre o fazer (SILVA e ARAÚJO, 2005). A observação de aulas torna-se, assim, um modo de aprender na interação que não depende apenas dos indivíduos "mais experientes" e essa é uma das características de uma CP: a aprendizagem mútua.

O Projeto de Observação de Aulas do NucLi Inglês-IsF da UFPR iniciou no segundo semestre de 2014 e teve, desde seu início até 2016, etapas de planejamento, preparação e aplicação, bem como momentos de reflexão crítica e reestruturação. $O$ projeto pode ser caracterizado como uma prática situada na $\mathrm{CP}$, que envolve diversas outras práticas situadas e exige, dos participantes, engajamento mútuo e repertório compartilhado para se chegar a um empreendimento comum, que, de modo geral, no projeto, seria o aperfeiçoamento pedagógico individual e também o coletivo, tendo como consequências imediatas a melhoria da qualidade das aulas e uma maior procura pelos cursos de inglês ofertados pelo Programa IsF na UFPR. Com formulários de feedback em mãos, previamente adaptados pelo grupo, cada aluno-professor da CP observava, mensalmente, no mínimo, uma aula de um de seus colegas, membros do grupo. As observações seguiam um cronograma colaborativamente estipulado para garantir que todos observassem aulas e também fossem observados, recebendo feedback. Estratégias de coaching foram discutidas no grupo e implementadas durante as observações e, em especial, durante as fases que compunham cada observação: 1) a pré-observação, composta de ao menos um encontro entre aluno-professor observado e observador antes da observação da aula, onde planejamento e materiais didáticos seriam

\footnotetext{
${ }^{21}[\ldots]$ teachers are clearly prime candidates to benefit from CoPs, as they can be powerful catalysts for enabling teachers to improve their practice.
} 
REVISTA X, Curitiba, volume 13, n.2, p.67-92, 2018.

discutidos, com o objetivo de "desenvolver com o professor observado um espírito de abertura e interesse de forma a afastar qualquer motivo de ansiedade" (REIS, 2011, p. 20), a observação, ou seja, a participação de um professor como coach de um colega durante uma aula, com data e horário previamente combinados e com a utilização do formulário de feedback, a ser entregue ao professor observado ao final da aula e, 3 ) pósobservação, para a discussão da aula entre os professores, observador e observado, com a leitura dos apontamentos colocados no formulário; nessa fase, o professor observado "deve ser encorajado a partilhar as suas impressões da aula e a inferir relações causais entre as suas ações e os resultados do aluno; ele deve ter um papel ativo e crítico do seu próprio ensino" (REIS, 2011, p. 12). Segundo Walesko e Luchesa (2015, p. 3482), “o projeto também possibilitou que os professores envolvidos aperfeiçoassem sua prática de ensino ao aprenderem novas estratégias e técnicas com os colegas”. Em uma pesquisa sobre o projeto as autoras receberam os seguintes relatos: "Ele (o projeto) oferece condições de observar práticas diferentes, realizadas por pessoas diferentes, frente a grupos diferentes, mostrando insights novos e abordagens que talvez não nos pareçam relevantes, ou que não nos tenham ocorrido”. (aluna-professora P. M.); “(...) contribuiu bastante para nosso desenvolvimento profissional (...) principalmente ao observarmos as aulas de outras colegas de trabalho, pois isso trouxe uma nova gama de ideias e estratégias a serem utilizadas em sala de aula que não são discutidas nas reuniões pedagógicas" (aluna-professora A. C.); "pude visualizar diferentes formas de realizar a mesma atividade, refletindo sobre como os métodos funcionavam, como atingiam os alunos, como podem ser adaptados em diferentes contextos e etc.". (alunaprofessora C. H.).

\section{Oficinas para discussão de textos teórico-metodológicos}

O Programa Idiomas sem Fronteiras e o NucLi Inglês-IsF da UFPR, desde seu início, se caracterizou como um espaço de formação de professores e preocupou-se com o desenvolvimento crítico-reflexivo dos professores em formação, necessário para uma aprendizagem e ensino mais dinâmico e autônomo. Por isso, as atividades práticas do grupo sempre estiveram acompanhadas de reflexões teóricas. Assim, leituras reflexivas e discussões em grupo sempre fizeram parte da rotina da equipe do Núcleo, especialmente ao longo das reuniões pedagógicas, semanalmente realizadas e que tinham como tópico principal questões relacionadas ao letramento crítico, multiletramentos e ensino/aprendizagem de língua inglesa. As propostas de tópicos 
REVISTA X, Curitiba, volume 13, n.2, p.67-92, 2018.

partiam sempre da equipe de alunos-professores, que afirmavam ter, na graduação em Letras Inglês, aulas bastante focadas no desenvolvimento de sua proficiência linguística e com raros momentos para tais discussões, pertinentes à sua formação docente. Além disso, alguns professores mencionaram que, como docentes em escolas de idiomas, também não tiveram oportunidades de reflexões teórico-metodológicas, pois as instituições pressupunham que para ser professor de língua bastava proficiência na língua, e, ainda, que tais reflexões deveriam fazer parte da formação dos professores em seu curso superior, e não em seu ambiente de trabalho.

Diante desse cenário e da exigência, por parte do Programa IsF, de atividades à distância durante recesso letivo, foram pensadas pela equipe de professores e coordenadores NucLi Inglês-IsF da UFPR, entre outras atividades, a leitura de vários textos como fundamentação teórica para sua prática pedagógica, a serem apresentados em Oficinas para discussão de textos teórico-metodológicos. Diferentemente de discussões teórico-práticas de rotina, conduzidas por coordenadores, nas oficinas cada aluno-professor da equipe foi responsável por liderar a discussão de um dos textos e os demais o liam e enviavam duas questões para um coordenador, que as repassava ao professor responsável. Com o auxílio de apresentações em power point, de resumos e das questões, em encontros de sexta-feira, um dos textos era estudado e discutido pela equipe, com base nas questões elaboradas pelos colegas. Essa prática incentivou o desenvolvimento do pensamento crítico-reflexivo do grupo, perceptível no discurso e na agência de seus membros, bem como no seu relacionamento interpessoal. Segundo a aluna-professora A.C. (2014) essa atividade "ajudou no desenvolvimento no âmbito teórico sobre como ser uma melhor professora e sobre como lidar com questões críticas pesadamente discutidas nos dias de hoje, como letramento crítico e interculturalidade". Para a aluna-professora L. S (2014), “[a] leitura e discussão de textos teóricos relacionados ao nosso ensino de Inglês como Língua Estrangeira expandiram nossa consciência de sala de aula". A professora em formação A. N. (2014), complementou ainda afirmando: "não havia tido contato com nada desse teor até então e foi possível aplicar muitas informações em minhas aulas".

Durante as oficinas para discussões teórico-metodológicas pôde-se observar, entre os praticantes do grupo IsF enquanto membros de uma $\mathrm{CP}$, participações de caráter pleno e de caráter periférico, características já descritas no referencial teórico sobre CPs deste texto, uma vez que percebia-se que nem todos sempre participavam ativamente das reflexões, comentando ou questionando os demais participantes; alguns 
REVISTA X, Curitiba, volume 13, n.2, p.67-92, 2018.

apenas ouviam (o que não significa que não participavam das reflexões) colocando-se numa posição mais marginal ou à margem dos colegas que participavam de forma periférica ou plena, participação essa que, entretanto, não deixou de ser importante para sua formação como professor. Como colocamos anteriormente, o modo e/ou a intensidade da participação dos praticantes se estrutura dialeticamente e depende do momento em uma CP.

\section{Workshops}

Como uma CP, o grupo do NucLi Inglês-IsF da UFPR possuía um objetivo em comum - o de aperfeiçoamento profissional pessoal e educacional coletivo, uma vez que acreditavam que o trabalho que realizavam melhoraria sua prática de ensino e contribuiria gradativamente para a melhoria da educação, que se daria pela aprendizagem da língua inglesa, ao menos para a comunidade interna da universidade. Wenger (1998a) sugere que o objetivo compartilhado surge de negociação, é definido no processo de seu alcance e cria um padrão de responsabilidade mútua. Para o autor, o senso de responsabilidade gera o desejo de trabalho eficaz e eficiente em direção ao objetivo e também a responsabilidade de se aderir a normas de comportamento esperadas para a comunidade. A prática de elaboração e realização constante de workshops pelos membros da Comunidade de Prática do NucLi Inglês-IsF da UFPR é um exemplo dessa característica de responsabilidade mútua em prol de um objetivo comum.

Ao longo de seu funcionamento, os alunos-professores, coordenadores e ETAs realizaram, em duplas, trios ou individualmente, diversos workshops sobre temas importantes para a prática docente no programa. Os temas, sempre relacionados ao ensino e aprendizagem e inglês, tais como "interculturalidade", "uso da tecnologia em sala de aula", "jogos", "música”, "dificuldades de pronúncia de falantes brasileiros de português", "vídeo", "língua e cultura" e "escrita acadêmica", nunca foram impostos pela coordenação ou pelos ministrantes das oficinas, mas sempre negociados com os membros do grupo conforme suas necessidades e esses puderam colaborar previamente e durante os workshops com leituras, ideias e atividades práticas. Os workshops, ao contrário das oficinas para discussão de textos teórico-metodológicos, eram práticas abertas à comunidade acadêmica da universidade, bem como a docentes do CELIN da UFPR e de outras instituições educacionais e registrados como eventos acadêmicos na universidade, que contavam com apoio do NAP da UFPR para sua realização. 
REVISTA X, Curitiba, volume 13, n.2, p.67-92, 2018.

\section{Divulgação do NucLiIsF e do exame TOEFL}

A equipe do NucLi Inglês-IsF da UFPR era também responsável pela divulgação dos cursos presenciais, exames TOEFL, eventos e outras atividades do núcleo. As atividades de divulgação incluíam panfletagem e apresentação do núcleo ao término de aplicações dos exames TOEFL, em Semanas Acadêmicas de cursos diversos na universidade, feiras, eventos para alunos e funcionários, nos restaurantes universitários e durante as matrículas de novos alunos, além de mini-palestras acordadas e realizadas junto às diversas coordenações de cursos de graduação. Tais atividades eram complementadas com a exposição de banners nos diversos campi da universidade, envio de e-mails a alunos e funcionários e informações em redes sociais e no site do núcleo.

A divulgação das atividades do NucLi Inglês-IsF da UFPR era uma prática organizada e realizada de forma cooperativa e colaborativa, a fim de que todos os membros da equipe participassem ativamente e pudessem sentir-se responsáveis pelos bons resultados obtidos, refletidos na procura dos cursos do núcleo. Todos realmente acreditavam nos resultados de seu trabalho e desenvolviam um senso de pertencimento e compromisso mútuo, características marcantes em Comunidades de Prática, que podem ser relacionados a três conceitos que, segundo Plastoff (apud HARA, 2009), são essenciais para que uma Comunidade de Prática seja bem-sucedida: a crença (believing), o comportamento (behaving) e o pertencimento (belonging). Ressaltamos que, no grupo do NucLi Inglês-IsF da UFPR, enquanto uma CP, tais conceitos podiam ser facilmente observados, não apenas com relação às atividades de divulgação de seu trabalho, mas também nas demais atividades descritas neste artigo. Hara (2009, apud CALVO et al, 2014) considera também que CPs podem desenvolver uma cultura de apoio, baseada na confiança mútua, de forma que a informação é compartilhada para apoiar tarefas coletivas. Tais características afetivas de apoio entre os membros das CPs podem ser atribuídas ao NucLi Inglês-IsF da UFPR, o que não significa que conflitos não existissem. Segundo Wenger (1998a, p. 77) a maioria das situações que envolvem engajamento interpessoal sustentado gera tensões e conflitos. Para Wenger "discordância, desafios e competição podem ser formas de participação" 22. Assim, esclarecemos que, tanto no trabalho de divulgação quanto em outras atividades, no

\footnotetext{
${ }^{22}$ Disagreement, challenges, and competition can all be forms of participation.
} 
REVISTA X, Curitiba, volume 13, n.2, p.67-92, 2018.

grupo do NucLi Inglês-IsF da UFPR enquanto uma CP "nem tudo eram flores" e que desentendimentos e críticas naturalmente aconteciam, mas faziam parte do crescimento dessa CP.

\section{Eventos e atividades inter/culturais}

Eventos inter/culturais eram realizados com frequência com o objetivo de promover um diálogo inter/cultural entre coordenadores, alunos-professores, ETAs e monitores e o público discente do NucLi Inglês-IsF da UFPR, além de também de oportunizar encontros para a prática da língua inglesa. A prontidão e engajamento da equipe durante a organização e participação nos eventos era impressionante, o que ressalta os sensos de crença, comprometimento e pertencimento, anteriormente descritos neste texto. Entre os eventos promovidos estão as Cultural Fridays (Sextas-feiras Culturais), com temas diversos, tais como "O Halloween no Brasil e no mundo", "Festas Juninas: Brasil e EUA" e o "Dia de Ação de Graças". Os ETAs também promoveram, com a participação de alunos-professores, festas e feiras (Potluck Party "Festa Americana" e a College Fair - "Feira sobre Intercâmbio Estudantil"), as sessões ISFlix (sessões de cinema com uma "bate-papo em inglês sobre os filmes assistidos) e os Road tripevents (eventos interculturais com foco em uma região estadunidense a cada encontro), além dos Clubes de Conversação (Conversation Clubs) e workshops sobre temas de interesse dos alunos (Pragmática, Educação nos EUA, Política, Cultura Americana e Escrita Acadêmica), realizados semanalmente.

Todos os eventos inter/culturais promovidos pela equipe do NucLi Inglês-IsF da UFPR aconteceram por meio da negociação de significados com os quais cada membro se identificava ou não. Assim, tornaram-se práticas colaborativas imprescindíveis para tal negociação enquanto, como já descrito no referencial teórico deste texto, uma experiência de aprendizagem, de reformulação e de constituição identitária, individual e coletiva, dos praticantes da CP.

\section{CONSIDERAÇÕES FINAIS}

Neste texto objetivamos analisar a estrutura e as práticas, ao longo dos anos de 2014 a 2016, do Núcleo do Língua Inglesa do Programa Idiomas sem Fronteiras da Universidade Federal do Paraná (NucLi Inglês-IsF da UFPR) enquanto um projeto de formação inicial de professores, caracterizando-o como uma Comunidade de Prática, da qual participamos. Para isso, buscamos aprofundar nosso conhecimento teórico e 
também buscar um histórico do núcleo desde o seu início. Fomos motivadas, em princípio, por discussões a respeito do tema "Comunidades de Prática", realizadas durante a disciplina "Formação do Professor nas Letras Estrangeiras", do curso de PósGraduação em Letras da UFPR de 2015. A partir das reflexões teóricas ao longo do curso percebemos o quão ricas eram as experiências que vivenciávamos no NucLi Inglês-IsF enquanto uma CP e que compartilhá-las, neste texto, seria uma forma de formalizar tal caracterização e de divulgar o trabalho realizado para que outros projetos similares possam ser desenvolvidos.

Os praticantes/participantes da CP NucLi Inglês-IsF da UFPR estiveram, por meio da interação em práticas discursivas e não-discursivas desenvolvidas, em constante formação e também formando identidades, individuais e coletivas. Como aponta a professora-bolsista P. M (2014):

[A] interação com as colegas foi positiva no sentido de proporcionar o intercâmbio de informações e experiências em sala de aula, oferecendo uma perspectiva sistêmica e ampla dos desafios e soluções para o ensino de diferentes conteúdos e de questões com os alunos.

Assim como as identidades individuais dos membros de uma $\mathrm{CP}$ estão em constante re/construção, sua identidade coletiva também está. A CP NucLi Inglês-IsF da UFPR transforma-se e será transformada por meio de mudanças internas e externas, de novos praticantes que trarão novas visões e novas ideias e também de novas visões e novas ideias de antigos praticantes. Porém é importante ressaltar que toda e qualquer transformação de uma CP ocorre por meio da interação colaborativa. Como afirma Jordão (2013):

Propostas de renovação e de mudança devem ser construídas de forma colaborativa entre os envolvidos no processo, que identificam em conjunto o que precisa ser mudado, por que e para quê, os instrumentos que dispõem para isso e as possibilidades de mudança à disposição.

Pensar no NucLi Inglês-IsF da UFPR como uma Comunidade de Prática em constante re/construção é pensar em uma nova possibilidade de formação inicial de professores. É pensar na formação crítico-reflexiva do professor para que seja capaz de aprender dialogicamente, aplicar teorias à prática e teorizar sua prática docente para alcançar independência informada e construir múltiplos saberes. 


\section{REFERÊNCIAS}

ALMEIDA, M. R. de; KLUGE, D. C.; WALESKO, A. M. H. Formação de Professores Bolsistas para o Programa Inglês sem Fronteiras (IsF)/ Núcleo IsF de Língua Inglesa (NucLi) na Universidade Federal do Paraná (UFPR): experiências locais e desafios constantes. In: SARMENTO, S.; ABREU-E-LIMA, D. MORAES FILHO, W. B. (orgs.) Do Inglês sem Fronteiras ao Idiomas sem Fronteiras: A construção de uma política linguística para a internacionalização. Brasília:Editora UFMG, p.217- 231, 2016.

BAKHTIN, M. Marxismo e filosofia da linguagem. 10 ed. Trad. MichelLahud e YaraF. Vieira. São Paulo: Hucitec, 2002.

BRADLEY, H. Fractured identities. Cambridge: Polity Press, 1996.

BRASIL. Ministério da Educação. Programa Idiomas sem Fronteiras. Disponível em: <http://IsF.mec.gov.br>. Acesso em: 18 jan. 2018.

BLOCK, D. Second Language Identities. New York: Continuum International Publishing Group, 2010.

BONINI, A. In: SILVA, K. A., ARAGÃO, R.C. (Org). Conversas com formadores de professores de línguas avanços e desafios. Campinas: Pontes Editores, p. 33-37, 2013.

BOURDIEU, P.; PASSERON, J. C. Reproduction in education, society, and culture. Thousand Oaks: Sage Publications, 1977.

CALDWELL, B. J. Networking Knowledge to achieve transformation in schools. In: KIMBLE, C.; HILDRETH, P. (Org.) Communities of Practice: creating learning environments for educators. IAP Information Age Publishing, Inc. United States of America, 2008.

CALVO, L.C.S.; FREITAS, M.A. et al (Org.) Comunidades de Prática: aspectos da formação de professores de línguas em foco. Coleção: Novas Perspectivas em Linguística Aplicada, vol. 35. Campinas, SP: Pontes, 2014.

FOGAÇA, F. C. Comunidades de Prática e a ilusão do jardim do Éden. In: MATEUS; OLIVEIRA (Org.) Estudos Críticos da Linguagem e Formação de Professores/as de Linguas: contribuições teórico-metodológicas. Campinas: Pontes, 2014.

FOGACA, F.C.; HALU, R.C. Comunidades de prática e construção identitária de formadores de professores em um programa de formação continuada. Rev. Bras. linguist. apl., Belo Horizonte, v. 17, n. 3, Set 2017, p. 427-454. Disponível em: $<$ http://www.scielo.br/scielo.php?script=sci_arttext\&pid=S1984-63982017000300427 \&lng=en\&nrm=iso $>$. Acesso em: 02 out. 2017.

FOUCAULT, M. Vigiar e punir. 2. ed. Petrópolis: Vozes, 1983. 
Politics and the Study of Discourse. In Burchell, G, Gordon, C and Miller, P (Org.) The Foucault Effect: Studies in Governmentality, Chicago: University of Chicago Press, 1991.

FOX, S. Communities of Practice, Foucault and Actor-Network Theory. Journal of Management Studies, v. 37, n. 6, 2000, p. 853-867.

FULBRIGHT. Fulbright U.S. Student Program. Disponível em: < https://us.fulbright online.org/about>. Acesso em: 11 mar. 2018.

GIDDENS, A. Modernity and self-Identity: Self and society in the late modern age. Stanford: Stanford University Press, 1991.

HALL, S. A identidade cultural na pós-modernidade. Rio de janeiro: DP\&A Editora, 1992.

HALU, R. C. Formação de formadoras de professoras de inglês em contexto de formação continuada (NAP-UFPR). Tese (Doutorado em Linguística). Universidade Federal do Paraná. Curitiba, 2010.

HARA, N. Communities of practice. Fostering peer-to-peer learning and informal knowledge sharing in the workplace. Information, science and Knowledge management, 13, Springer-Verlag Berlin Heidelverg, 2009.

JORDÃO, C. M. In: SILVA, K. A.; Aragão, R.C. (Org.). Conversas com formadores de professores de línguas avanços e desafios. Campinas: Pontes Editores, p. 77-90, 2013.

KANNO, Y.; NORTON, B. Imagined communities and educational possibilities: introduction. Journal of Language, Identity and Education, Abingdon, v. 2, n. 4, p. 241- 249, 2003.

KIMBLE, C.; HILDRETH, P. (Org.) Communities of Practice: creating learning environments for educators. IAP Information Age Publishing, Inc. United States of America, 2008.

LAVE, J. Cognition in practice: Mind, Mathematics and Culture in Everyday Life. Cambridge, England: Cambridge University Press, 1988.

LAVE, J.; WENGER. E. Situated Learning: legitimate peripheral participation. New York: Cambridge University Press, 1991.

NORTON, B. Identity and language learning. Bristol: Multilingual Matters, 2013.

REIS, P. Observação de Aulas e Avaliação do Desempenho Docente. Ministério da Educação. Lisboa, Conselho Cientifico para a Avaliação de Professores, 2011. Disponível em: <http://www.ccap.min-edu.pt/docs/Caderno_CCAP_2->.Acesso em: 15 jun. 2015. 
SANTOS, E. M. Abordagem Comunicativa Intercultural (ACIN): uma proposta para ensinar e aprender língua no diálogo de culturas. Campinas: 2004. Tese. Universidade Estadual de Campinas, 2004.

SANTOS, V. C. ; ARROIO, A. A formação de professores em comunidades de prática: o caso de um grupo de professores de química em formação inicial. Química Nova, 38(1), p. 144-150, 2015.

SARMENTO, S.; ABREU ELIMA, D. M.; MORAES FILHO, W. B. (Org.). Do Inglês sem Fronteiras ao Idiomas sem Fronteiras: a construção de uma política linguística para a internacionalização. Belo Horizonte: Editora UFMG, 2016.

SARUP, M. Identity, culture and the postmodern world. Edinburgh: Edinburgh University Press, 1996.

SILVA, E. M.; ARAÚJO, C. M. Reflexão em Paulo Freire: uma contribuição para a formação continuada de professores. V Colóquio Pernambuco (UFPE), 2005. Disponível em: <http://189.28.128.100/nutricao/docs/Enpacs/pesquisaArtigos/reflexao_ em_paulo_freire_2005.pdf $>$. Acesso em: 30 jul. 2015.

SMITH, A. K.; WOHLSTETTER, P. Reform through social networks: a new kind of authority and accountability. Educational Policy.15(4), p. 499-519, 2001.

VYGOTSKY, L. S. Mind in society. Cambridge, MA: Harvard University Press, 1978.

. A Formação Social da Mente. São Paulo: Martins Fontes. 5a edição, 1994.

Pensamento e linguagem. São Paulo: Martins Fontes, 1988.

WALESKO, A. M. H; LUCHESA, M. M. Colaboração, Reflexão, Ação: A Experiência de um Projeto de Observação de Aulas na Formação Inicial de Professores. Anais do XII Congresso Nacional de Educação - Educere - Pontifícia Universidade Católica do Paraná, Curitiba, p. 34820-34830, 2015.

WENGER, E. Communities of practice: learning, meaning and identity. Cambridge University press, New York, 1998a.

WENGER, E. Communities of practice: learning as a social system. The Systems Thinker, Colorado, v. 9, n. 5, p. 1-10, 1998 b.

Communities of Practice and Social Learning Systems. Vol. 7 (2), SAGE Social Science Collections: London, Thousand Oaks, CA e New Delhi, 2000.

Communities of Practice and Social Learning Systems: the Career of a Concept. In: Blackmore C. (eds.) Social Learning Systems and Communities of Practice. Springer: London, 2010, p. 179-198.

WENGER, E.; McDERMOTT, R; SNYDER, W.M. Cultivating communities of practice: a guide to managing knowledge. Boston: Harvard Business School Press, 2002. 